\title{
Livro didático em educação física: as experiências públicas de João Pessoa e do Paraná
}

\author{
Didactic book in physical education: the public experiences of João Pessoa \\ and Paraná
}

Camila Ursulla Batista Carlos ${ }^{1 *}$, José Pereira de Melo ${ }^{2}$

ARTIGO ORIGINAL | ORIGINAL ARTICLE

\begin{abstract}
No cotidiano escolar, comumente utilizado em vários componentes curriculares, o livro didático aparece como um dos materiais possíveis para auxiliar o exercício docente. Tal recurso, utilizado tanto para o docente quanto para o estudante, permite um encadeamento do que deve ser pauta nas relações educativas, através de propostas de atividades e textos que norteiam discussões, vivências e pesquisas. Foi no Estado do Paraná o pioneirismo na produção do livro didático público para a Educação Física escolar, uma iniciativa similar encontrada no Nordeste, é a publicação do Livro Público do Município de João Pessoa, capital da Paraíba. A pesquisa tem o objetivo principal de analisar os livros didáticos para o ensino da Educação Física escolar desses dois sistemas públicos de ensino, que contemplam níveis de ensino diferentes e representativos para a área de atuação profissional, considerando as configurações das obras e seus conteúdos. Com o caráter qualitativo, a pesquisa se encaminha para as discussões a partir da análise de conteúdo proposta por Bardin (2011). Por terem a característica da disponibilidade online podem servir de material de apoio para outros professores de outros sistemas de ensino, não exclusivamente para aquele espaço geográfico que foi primeiramente pensado e escrito.
\end{abstract}

Palavras-chave: educação física e treinamento, livros, ensino fundamental e médio.

In everyday scholastic life, generally used in many curricular components, the didactic book shows up like one of the possible materials to auxiliary the university professor. Such resource is used as well for university professor and student, allows the chaining of what will be the agenda in the education's relations, through proposes of activities and texts that will guide discussions, life experiences, and search. Was in the State of Paraná the pioneering to produce the public didactic book for the scholar Physical Education, a similar initiative found on Nordeste, it is the publication of the Public Book of the City of João Pessoa, Paraiba's capital. The searching has the main objective of analyses the didactic books for the teaching of the scholar Physical Education of these two teaching public systems, that contemplates different levels of teaching and representatives for the professional field, considering the work configurations and his contents. With the qualitative character, the searching route to the discussions starting from the analysis of content proposed by Bardin (2011). For having the online available characteristic, they could be used as a support material to other professors of another teaching systems, not exclusively to that geographic space that was first thought and write.

Keywords: physical education and training, books, education, primary and secondary.

\footnotetext{
${ }^{1}$ Universidade do Estado do Rio Grande do Norte, Mossoró, Rio Grande do Norte, Brasil

${ }^{2}$ Universidade Federal do Rio Grande do Norte, Natal, Rio Grande do Norte, Brasil

* Autor correspondente: camilaursulla@hotmail.com
} 


\section{INTRODUÇÃO}

Muitas críticas são tecidas aos livros didáticos, principalmente relacionados ao seu caráter ideológico, aos estereótipos de sociedade, ao mercado editorial - afinal ele também é um produto - e também à acomodação de professores e professoras que utilizam esse recurso quase exclusivamente como única fonte de discussão, entre muitos outros apontamentos, mas é um material que está na escola e que vem sendo discutido e pleiteado para a Educação Física.

$\mathrm{O}$ formato do texto, as imagens, o encadeamento de ideias, a linguagem utilizada, as propostas de vivências, a intencionalidade do que está posto - e o que também não está -, a proposição de outras fontes de informação e/ou conhecimento, são elementos que estão presentes nos livros didáticos e afetam direta ou indiretamente aqueles que o utilizam.

Entretanto, o livro didático aparece como um dos materiais possíveis para auxiliar os professores e professoras para nortear a prática pedagógica. Tal recurso, utilizado tanto para o docente quanto para o estudante, presente tanto nas escolas públicas quanto particulares, permite um encadeamento do que deve ser pauta nas relações educativas, através de propostas de atividades e textos para nortear as discussões e vivências.

Foi no Estado do Paraná o pioneirismo na produção do livro didático público para o referido componente, destinado tanto ao uso do professor quanto do aluno, encontra-se em sua $2^{a}$ edição, em circulação desde 2006. Uma iniciativa similar encontrada em outra região do país, no nordeste, é a publicação do Livro Público do Município de João Pessoa, capital da Paraíba, disponibilizada desde o ano de 2012. Apesar de ser um tipo de publicação recente, pouco difundida e ainda polêmica para a área, faz-se necessário investigar o que está em circulação.

A seleção destas também foi respaldada pela sua disponibilidade online, facilitando o acesso para a pesquisa e manuseio, além de terem uma característica importante e comum, serem frutos da construção coletiva entre professores e professoras dos respectivos sistemas de ensino livros pensados a partir de formações continuadas
- e contribuição de docentes que atuam no Ensino Superior.

A partir desse contexto, o presente trabalho materializa-se com o objetivo principal de analisar livros didáticos para o ensino da Educação Física escolar de dois sistemas públicos de ensino, que contemplam níveis de ensino diferentes e representativos para a área de atuação profissional, considerando as configurações das obras e seus conteúdos.

\section{MÉTODO}

Esta pesquisa caracteriza-se com o caráter qualitativo, e se encaminha para as discussões a partir da análise de conteúdo. $\mathrm{O}$ trato metodológico para esse tipo de material é fundamentado na análise de conteúdos proposta por Bardin (2011).

\section{Instrumentos e Procedimentos}

Para tal, foi eleito um conjunto de seções frente à diversidade de elementos encontrados na estrutura dos livros, partindo de elementos didáticos que guiaram a leitura flutuante, foram identificados tópicos referentes à Matriz teórica, Função da Educação Física na escola (Objetivos da Educação Física na escola), Seriação, Blocos de Conteúdos/ Eixos temáticos, Sistematização dos conteúdos. Esses elementos foram importantes para a construção das categorias de análises desta pesquisa, a saber: Matriz teórica, Objetivo da Educação Física na escola, Conteúdos. Dentre as categorias de análise de conteúdo propostas por Bardin (2011), a análise categorial aproxima-se melhor da proposta da pesquisa.

\section{RESULTADOS E DISCUSSÃO}

Contendo 248 páginas, e em sua segunda edição, O livro didático público do Paraná, destinado à derradeira etapa da Educação Básica, é um produto do Projeto Folhas. Em 2004, junto com o processo inicial da elaboração das Diretrizes Curriculares da rede, teve o início o Programa de Formação Continuada para professores que assim se intitulava Projeto Folhas. Os autores teriam autonomia para definir o recorte específico do conteúdo que desejaria desenvolver um Folhas, desde que esse recorte 
tivesse como referência os Diretrizes Curriculares Estaduais e seus conteúdos estruturantes (Costa, 2014).

De acordo com Souza Júnior et al. (2015), o livro didático público do Paraná é responsável por gerar um aumento, mesmo que tímido, das produções de livros didáticos para a Educação Física, assim como estudos sobre o tema, a partir de sua primeira publicação. Essa demanda desperta a necessidade de se pensar criticamente sobre tal recurso na Educação Física escolar. Nesse sentido, há um apontamento no texto de apresentação do livro didático sobre esse ineditismo:

O livro didático público do Paraná é apontado por Rodrigues e Darido (2011) com um perfil diferenciado dos demais livros didáticos publicados em território nacional, pois teve como meta ser constituído pela produção de professores da rede estadual e com distribuição gratuita.

O outro livro didático público que é de interesse dessa pesquisa, é o da cidade de João Pessoa. Este que é uma construção coletiva, fruto dos cursos de formação continuada oferecida aos professores da rede municipal de ensino, sob a coordenação de professores vinculados ao Laboratório de Estudos e Pesquisas em Educação Física, Esporte e Lazer da Paraíba (LEPELPB), da Universidade Federal da Paraíba (UFPB) e de outras instituições de ensino superior. O livro didático apresenta 95 páginas e é destinado aos alunos e alunas do $5^{\circ}$ ao $9^{\circ}$ ano do Ensino Fundamental.

Tabela 1

Elementos didáticos

\begin{tabular}{|c|c|c|}
\hline & João Pessoa ( $5^{\circ}$ ao $9^{\circ}$ ano) & Paraná (Ensino Médio) \\
\hline Matriz teórica & $\begin{array}{l}\text { Cultura Corporal - Teoria pedagógica } \\
\text { histórico-crítica e metodologia de ensino } \\
\text { crítico-superadora } \\
\text { "Por que cultura corporal como objeto? Por } \\
\text { que o que entra na escola como componente } \\
\text { curricular é a produção social da humanidade } \\
\text { acumulado } \\
\text { historicamente nas relações de produção da } \\
\text { vida. Portanto, a Educação Física trata na } \\
\text { escola do que a humanidade acumulou nas } \\
\text { suas relaçães de produção e reprodução da } \\
\text { vida que lhe dão sentido e significado } \\
\text { histórico" (p.II, prefácio). }\end{array}$ & $\begin{array}{l}\text { Cultura Corporal } \\
\text { "As discussões e práticas fundamentadas na Cultura } \\
\text { Corporal possibilitam a problematização de questões } \\
\text { importante para o desenvolvimento crítico do aluno } \\
\text { e a desnaturalização de alguns conceitos como, por } \\
\text { exemplo, o de que a competitividade individualista, } \\
\text { dos tempos atuais é inata ao ser humano. O ser } \\
\text { humano é entendido, aqui, como social, histórico, } \\
\text { inacabado e, portanto, em constante transformação. } \\
\text { Essa compreensão exige que da Educação Física uma } \\
\text { abordagem teórica que contextualize as práticas } \\
\text { corporais, relacionando-se aos interesses políticos, } \\
\text { econômicos, sociais e culturais que as constituíram" } \\
\text { (p.11, apresentação). }\end{array}$ \\
\hline $\begin{array}{lr}\text { Função } & \text { da } \\
\text { Educação } & \text { Física } \\
\text { na } & \text { escola } \\
\text { (Objetivos } & \text { da } \\
\text { Educação } & \text { Física } \\
\text { na escola) } & \\
\end{array}$ & $\begin{array}{l}\text { "Ampliar nossos conhecimentos, nos } \\
\text { instrumentalizar, analisar, sintetizar e criar } \\
\text { elementos novos da cultura corporal" (p.II, } \\
\text { prefácio) }\end{array}$ & $\begin{array}{l}\text { "Construir possibilidades diversas de análise e } \\
\text { (re)criação das práticas corporais, por meio das } \\
\text { variadas manifestações da Cultura Corporal, } \\
\text { aprofundando a reflexão crítica dos alunos acerca dos } \\
\text { conhecimentos próprios desta disciplina escolar" } \\
\text { (p.11, apresentação). }\end{array}$ \\
\hline Conteúdos & Jogos, Es & ástica, Lutas e Dança \\
\hline $\begin{array}{l}\text { Blocos de } \\
\text { Conteúdos/ Eixos } \\
\text { temáticos }\end{array}$ & $\begin{array}{l}\text { Jogos - Jogar e/ou brincar: Vamos entender; } \\
\text { Os jogos eletrônicos e os jogos populares; } \\
\text { Jogos Cooperativos: uma possibilidade para } \\
\text { todos. } \\
\text { Esporte - A prosa e a poesia no futebol ; } \\
\text { Futebol sem impedimento (o futebol; futebol } \\
\text { feminino; o futebol feminino na Paraíba; E o } \\
\text { futebol paraibano?). } \\
\text { Dança - Origem de tudo e estilos de dança; } \\
\text { Danças populares: Compreendendo nossas } \\
\text { raízes; O Balé; Dança Moderna; Dança } \\
\text { Contemporânea; Dança de Rua/ Danças } \\
\text { Urbanas; Quem pode dançar? Meninos ou } \\
\text { meninas: Questões de Gênero; Funções da } \\
\text { Dança; Dança da moda: Moda da dança. } \\
\text { Ginástica - Um pouco da história da ginástica; } \\
\text { As escolas de ginástica: Saúde, disciplina e } \\
\text { civismo; A chegada da ginástica no Brasil. }\end{array}$ & $\begin{array}{l}\text { Esporte - O futebol para além das quatro linhas; A } \\
\text { relação entre a televisão e o voleibol no } \\
\text { estabelecimento de regras; Eu faço esporte ou sou } \\
\text { usado pelo esporte? } \\
\text { Jogos - Competir ou cooperar: eis a questão; O jogo } \\
\text { é jogado e a cidadania é negada. } \\
\text { Ginástica - O circo como componente da ginástica; } \\
\text { Ginástica: um modelo antigo com roupagem nova? } \\
\text { Ou uma nova maneira de aprisionar corpos? ; Saúde } \\
\text { é o que interessa? O resto não tem pressa! ; Os } \\
\text { segredos do corpo. } \\
\text { Lutas - Capoeira: jogo, luta ou dança? ; Judô: a } \\
\text { prática do caminho suave. } \\
\text { Dança - Quem dança seus males; Influência da Mídia } \\
\text { sobre o Corpo do Adolescente; Hip Hop - movimento } \\
\text { de resistência ou consumo? }\end{array}$ \\
\hline
\end{tabular}


O prefácio escrito por Celi Nelza Zulke Taffarel (Professora Dra. Titular Pesquisadora do CNPq 1D - GRUPO LEPEL/FACED/UFBA) e Claudio Lira Santos Júnior (Professor Dr. Adjunto FACED/UFRBA - Departamento III Coordenação Grupo LEPEL/FACED/UFBA) apontam elementos importantes abordados pelo livro didático, a saber: Ser fruto dos cursos de formação continuada em exercício, nos anos em 2008, 2009 e 2010 em parceria com o LEPELPB/UFPB e outras instituições de ensino superior - já dito anteriormente, de forma coletiva e assumida publicamente (João Pessoa, 2012).

Em seu texto de apresentação, Jorge Fernando Hermida (LEPELPB/UFPB) aponta o pioneirismo e representatividade do Estado do Paraná ao construir um livro didático público para a Educação Física considerando os professores e professoras que atuam nas escolas e como essa configuração influenciou a construção do livro didático da cidade de João Pessoa.

A matriz teórica, ou o fio condutor da construção do livro, é comum às duas obras. A cultura corporal embasa a fundamentação destas, uma escolha entre muitas abordagens pedagógicas que fundamenta $\mathrm{o}$ ensino da Educação Física na escola. A maior representação dessa concepção aparece no livro Metodologia do Ensino de Educação Física, publicado 1992 e construído por um coletivo de autores, sendo estes: Carmen Lúcia Soares, Celi Nelza Zülke Taffarel, Elizabeth Varjal, Lino Castellani Filho, Micheli Ortega Escobar e Valter Bracht. A partir desse enfoque deve-se tratar o conhecimento da Educação Física, a cultura corporal - que ancora a expressão corporal como linguagem social e historicamente construída -, abordando os temas a partir do contexto real da escola, da cidade e da região (Coletivo de autores, 1992).

A função da Educação Física na escola, ou os objetivos da Educação Física na escola também está relacionado à matriz curricular, entretanto exprime de forma específica como se configura essa presença. Além da legitimação legal do componente curricular, há de se pensar o porquê desta ocupar espaço e tempo nos currículos escolares. Sendo a matriz comum aos dois sistemas públicos de ensino, os objetivos propostos acabam se aproximando.

Em relação à seriação, ou seja, a organização do conhecimento em séries, não há indícios desse tipo de organização nas obras analisadas.

Os conteúdos estão relacionados ao desenvolvimento das atividades corporais e à explicitação das suas significações objetivas, em que são suscetíveis de ser sistematizados em nível escolar. Nesse ínterim, aponta:

São eles, numa ordem arbitrária: Jogo; Esporte; Capoeira; Ginástica e Dança. Cada um deles deve ser estudado profundamente pelo (s) professor (es), desde a sua origem histórica ao seu valor educativo para os proprósitos e fins do currículo. Dizer ordem arbitrária significa que não há uma ordem rígida para organizar o programa, colocando primeiro o jogo, segundo a data etc. $\mathrm{O}$ professor pode dar a ordem necessária aos interesses da turma ou também tratar deles simultaneamente (coletivo de autores, 1992, p. 64).

Em relação ao bloco de conteúdos/eixos temáticos temos o desmembramento, ou seja, o que de pertinente foi elencado para cada conteúdo escolhido e sua organização. Para a realidade específica de Educação Física, Darido e Rangel (2008), apontam que no modelo em que os alunos são quem decidem o que vão fazer na aula, escolhendo a modalidade que querem praticar, a função do professor fica restrita a entregar a bola e marcar o tempo do jogo, ou seja, praticamente não existe nenhuma intervenção pedagógica.

Para o livro do estado do Paraná, a organização dos conteúdos não segue por capítulos, mas pela junção de Folhas que contemplam o mesmo conteúdo estruturante. Nessa perspectiva, os Folhas são textos que abordam um conteúdo estruturante de forma específica e apresenta discussões, imagens e elementos metodológicos específicos. Com o olhar mais focado alguns elementos na construção do livro chamaram a atenção, um deles foi constatar a independência dos Folhas do mesmo conteúdo estruturante.

O conteúdo Esporte consegue tematizar duas práticas corporais específicas, o futebol e o 
voleibol, a partir da gênese do esporte moderno, da espetacularização do fenômeno esportivo e sua forte representação social.

No que diz respeito ao Jogo, os Folhas situam o conteúdo a partir da cultura e da competição, fazendo aproximação com a lógica do sistema capitalista e aponta os jogos cooperativos enquanto possibilidade de convívio social e como contraponto a competição exacerbada.

Sobre o conteúdo Ginástica, compilando as discussões dos Folhas, é situada historicamente como forma de educar os corpos, é tematizado a importância dos Métodos Ginásticos, bem como a referência do circo para as práticas corporais desse conteúdo. Situa, ainda, a relação entre os estereótipos, as intervenções corporais e as relações de consumo, discute a perspectiva da saúde para além do comprometimento individual, a influência da mídia e os modismos que envolvem as atividades físicas.

As Lutas são tematizadas a partir da perspectiva da Capoeira e do Judô. O conteúdo aborda os elementos históricos, o praticante, o espaço e as relações de hierarquia nas referidas práticas corporais. A Capoeira ainda é discutida a partir da perspectiva de movimento de resistência e sua representatividade é destacada enquanto folclore nacional. No que compete especificamente ao Judô tem-se a notoriedade do processo de esportivização e espetacularização dessa prática corporal, além da analogia ao combate/luta e a sociedade capitalista.

Sobre o conteúdo Dança o livro tematiza a perspectiva de produção de significados e essa prática corporal como elemento cultural. Situa a passividade e não reflexão diante da indústria cultural, bem como frisa a banalização de alguns comportamentos advindos das "danças prontas". Discute a indústria da juventude, o belo, situa o movimento HIP HOP, sua relação com os movimentos sociais e a imparcialidade da mídia.

Cada conteúdo estruturante tem uma introdução, que se utiliza de imagem sobre o tema, e apresenta um panorama geral sobre o que será discutido nos Folhas que constituem aquele grupo. Logo em seguida há os Folhas, com seus textos específicos, referenciados e ilustrados, bem como com a identificação dos autores e autoras responsáveis e suas respectivas vinculações institucionais. Há sempre três eixos de organização para cada Folhas: Debate, Pesquisa e Atividade. Ao final de cada texto encontram-se as referências bibliográficas, os documentos consultados online e um espaço destinado para anotações.

O livro didático público do Município de João Pessoa também se ancora na cultura corporal para embasar as relações educativas da Educação Física na escola. Perspectivando ampliar, instrumentalizar, analisar, sintetizar e criar novos elementos concernentes à cultura corporal, o livro traz em seus capítulos - opção de organização textual - os conteúdos esporte, jogo, dança e ginástica, e destina-se para o Ensino Fundamental.

Situando o conteúdo Jogo, o livro opta por discutir inicialmente a relação entre jogo e brincadeira, questionando suas aproximações e possíveis distanciamentos. Aborda ainda os jogos eletrônicos, jogos populares e os jogos cooperativos

Sobre o esporte, conteúdo caro e quase hegemônico nas aulas de Educação Física escolar, houve uma exclusiva discussão sobre o futebol, excluindo todas as outras práticas esportivas. $\mathrm{O}$ que intriga e dar a pensar, pois mesmo sendo um esporte de grande representatividade, amplamente praticado e veiculado pelas das mídias de massa, tem-se nessa escolha uma simplificação muito grande da obra em tematizar apenas essa modalidade para o referido conteúdo. O capítulo foi dividido em dois momentos, tematizando o futebol na perspectiva do esporte de rendimento, quase que exclusivamente abordando elementos que orbitavam as Copas do Mundo, e no segundo momento apresentou-se mais articulado, com linguagem mais acessível aos estudantes e estabeleceu conexões importantes com aquela realidade local/regional e dando visibilidade ao feminino, o lugar da mulher na sociedade - suas lutas -, bem como aquelas que jogam futebol.

No capítulo destinado ao conteúdo Dança percebe-se uma pulverização das muitas perspectivas e linguagens da Dança, sem dar profundidade a nenhuma delas, o que dá uma visão panorâmica, entretanto frágil para pensar o conteúdo. Um ponto salutar que deve ser 
destacado são as inferências fortes sobre determinadas práticas corporais e gênero.

No que compete a Ginástica tem-se um capítulo com uma perspectiva um pouco distante da realidade dos alunos, com um cunho muito histórico e construído com muitas citações e pouca proximidade com a realidade do Ensino Fundamental.

Foi possível ainda visualizar problemas de edição no livro, e não há interação entre seus capítulos e a pouca aproximação com outras disciplinas.

Há uma relação de proximidade entre os dois livros. Foram percebidos em alguns trechos abordagens muito próximas dos conteúdos, por terem a mesma matriz teórica. Inclusive utilizando recursos metodológicos similares, como a apreciação do filme Billy Elliot - conteúdo Dança -, a analogia entre o futebol e o ópio; esporte como fenômeno de alienação; propaganda política da Copa de 1970 - conteúdo Esporte -, e a abordagem dos Métodos Ginásticos - conteúdo Ginástica, por exemplo. A relação entre as estruturas dos livros didáticos e a proposição encontrada nos editais do PNLD (Programa Nacional do Livro Didático) não é a mesma, o que afirma a característica assumida na construção coletiva das obras - professores e professoras que estão no chão da escola e profissionais que estão nas Secretarias e Universidades - e não o perfil de obras pensadas e escritas a partir de editoras, ou seja, de profissionais qualificados para essa produção.

\section{CONCLUSÕES}

Pensar um livro didático para a Educação Física escolar é refletir sobre o corpo, a intencionalidade de movimento, a diversidade das práticas corporais, a organização dos seus conteúdos, as múltiplas estratégias de ensino, temas discussões, vivências e instrumentos e momentos de avaliação.
Acreditamos que há espaço para livros didáticos de Educação Física, apesar da pouca tradição desse material na realidade dessas aulas. Os livros didáticos, aqui em questão, apresentam a disponibilidade online e podem servir de material de apoio para outros professores de outros sistemas de ensino, não exclusivamente para aquele espaço geográfico que foi primeiramente pensado e escrito. Entretanto é necessário refletir que o material, apesar de colaborar com o fazer docente não pode ser limitador do seu fazer pedagógico.

\section{Agradecimentos:}

Nada a declarar

Conflito de Interesses:

Nada a declarar.

\section{Financiamento:}

Nada a declarar

\section{REFERÊNCIAS}

Bardin, L. (2011). Análise de Conteúdo. São Paulo: Edições 70.

Coletivo de autores. (1992). Metodologia do Ensino de educação física. São Paulo: Cortez.

Costa, C. F. (2014). O livro didático de educação física para o ensino médio do Estado do Paraná: uma proposta marxista? 2014. 131f. Dissertação (Mestrado em Educação) - Programa de Pós Graduação em Educação, Universidade Federal do Paraná, Curitiba.

João Pessoa. (2012). Livro didático público: educação física. MACIEIRA, J. de A., CUNHA, F. J. de P; Xavier Neto, L. P. (Orgs.). João Pessoa: Editora Universitária da UFPB.

Paraná (estado). (2006). Educação Física. Vários Autores. Curitiba: SEED-PR.

Rodrigues, H. A.; Darido, S. C. (2011). O livro didático na educação física escolar: a visão dos professores. Motriz, 17(1), 48-62.

Souza Júnior, M. (2015). Educação Física e o livro didático: entre o hiato e o despertar. Movimento, 21 (2), 479-493. 